\title{
DESI-MS analysis of human fluids and tissues for forensic applications
}

\author{
Anna Wójtowicz ${ }^{1,2} \cdot$ Renata Wietecha-Posłuszny ${ }^{1,2}$ \\ Received: 16 October 2018 / Accepted: 18 March 2019 / Published online: 9 April 2019 \\ (c) The Author(s) 2019
}

\begin{abstract}
Desorption electrospray ionization mass spectrometry (DESI-MS) is an ambient ionization technique which application in forensic chemistry appears to be very promising. The technique enables rapid in situ analyses without the need of elaborate sample preparation. Nowadays, many DESI-MS applications in forensics, medical diagnostics and food control have been already reported in the literature. The study summarizes the latest DESI-MS forensic applications in the analysis of biological fluids and tissues, i.e., fingerprints, skin, urine and blood, in which the interest has grown during the recent years. In the publication presented below, the use of blood samples in dried blood spots is also included. The analysis reported covers mainly the determination of medicines and illicit drugs content in biological fluids and tissues, where great DESIMS potential in screening and drugs identification was recognized. Furthermore, the examples of explosives and condoms components detection are also present.
\end{abstract}

$\begin{array}{ll}\begin{array}{l}\text { Abbreviations } \\ \text { ACN }\end{array} & \begin{array}{l}\text { Acetonitrile } \\ \text { Dried blood spots } \\ \text { DBS } \\ \text { DESI-MS }\end{array} \\ \begin{array}{l}\text { Desorption electrospray ioniza- } \\ \text { tion mass spectrometry } \\ N, N \text {-dimethylformamide } \\ \text { Ethanol }\end{array} \\ \text { EtOH } & \begin{array}{l}\text { Gas chromatography-mass } \\ \text { spectrometry }\end{array} \\ \text { GC-MS } & \text { Gunshot residues } \\ \text { GSR } & \begin{array}{l}\text { Liquid chromatography tandem } \\ \text { mass spectrometry }\end{array} \\ \text { LC-MS/MS } & \text { Limit of detection } \\ \text { LOD } & \text { Limit of quantification } \\ \text { LOQ } & \text { Methanol } \\ \text { MeOH } & \text { Over-the-counter drugs } \\ \text { OTC drugs } & \text { Poly(methyl methacrylate) } \\ \text { PMMA } & \text { Polytetrafluoroethylene } \\ \text { PTFE } & \text { Trinitrohexahydro-1,3,5-triazine } \\ \text { RDX } & \text { Thin-film microextraction } \\ \text { TFME } & \text { Thin liquid membrane extraction } \\ \text { TLME } & \end{array}$

Renata Wietecha-Posłuszny

wietecha@chemia.uj.edu.pl

1 Laboratory for Forensic Chemistry, Faculty of Chemistry, Jagiellonian University, Gronostajowa 2, 30-387 Kraków, Poland

2 Department of Analytical Chemistry, Jagiellonian University, 2, Gronostajowa St, 30-387 Kraków, Poland

\section{TLC \\ TNT \\ QuEChERS extraction \\ Thin-layer chromatography \\ 2,4,6-Trinitrotoluene \\ Quick, easy, cheap, effective, rugged, and safe extraction}

\section{Introduction}

Desorption electrospray ionization mass spectrometry is an ambient ionization technique that enables both specimen introduction and ionization in one particular event. DESIMS analysis is performed in a native sample's environment, at atmospheric pressure with minimal preparation [1,2]. Figure 1 shows the idea of a typical DESI-MS setup which consists of solvent delivery line, nebulizing gas $\left(\mathrm{N}_{2}\right)$, high voltage power supply, and $\mathrm{x}, \mathrm{y}, \mathrm{z}$-moving stages with $\mathrm{z}$-axis used only for initial positioning. The setup also involves $\mathrm{x}, \mathrm{y}-$ axes, which enable sample positioning during the analysis and provide the independent control of the sample position as well as the position of the ion source in relation to the mass spectrometry inlet [1]. Briefly, the analysis process includes transportation of a solvent in a form of charged micro-droplets spray from pneumatically assisted needle to the sample surface, analytes' interaction with the solvent, their subsequent desorption into gas phase and ionization. Further on, the ionized compounds are moved to the mass spectrometer through an interface, where the solvent is removed under heat and vacuum and analytes are detected $[1,2]$. 
Fig. 1 The idea of a typical DESI-MS setup and an example of typical appearance of a dried blood spot card after DESI analysis

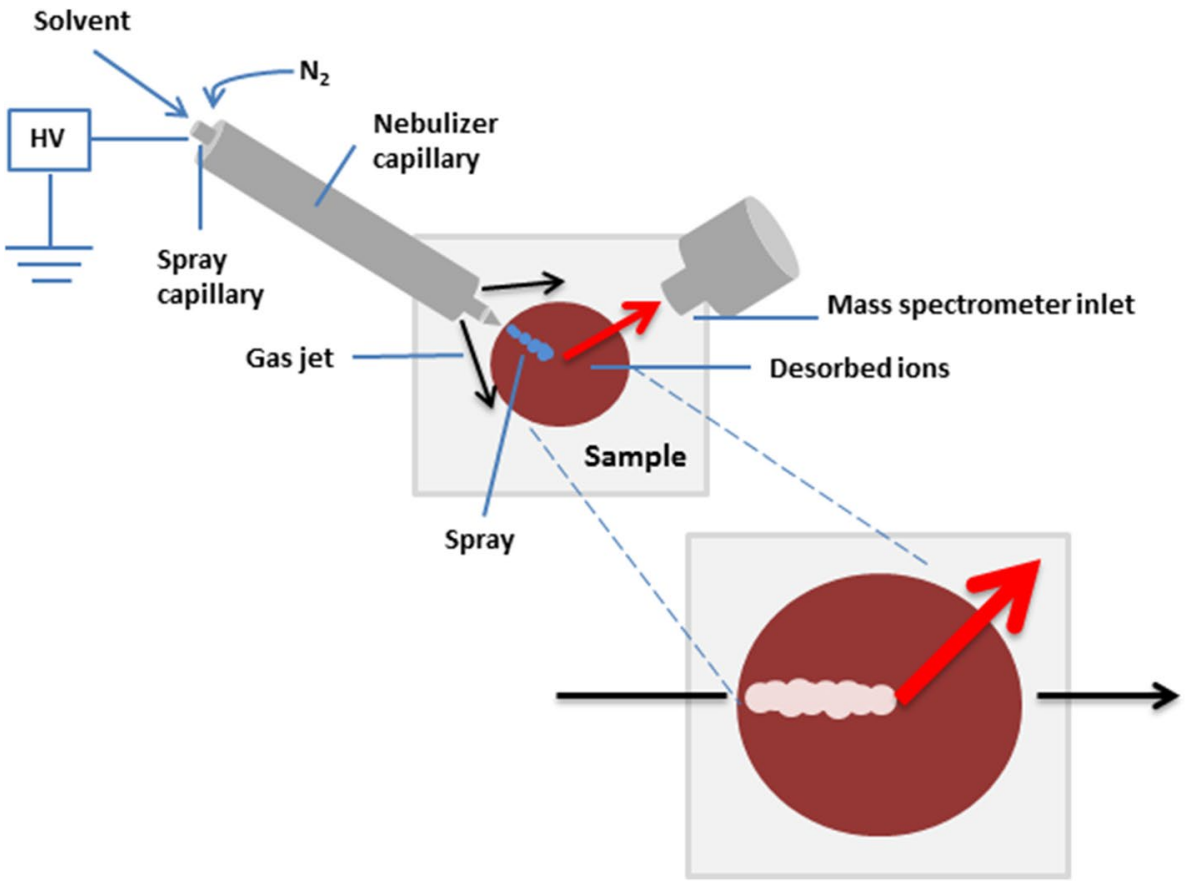

The signal is highly dependent on instruments parameters such as distances and angles between described elements as well as operating conditions of the electrospray [3]. Moreover, the solvent spray composition is crucial for the desorption and ionization mechanism in DESI-MS. Its effect on signal intensity and resolution was explored by Green et al. [4]. Methanol/water is the most commonly used solvent system; however, there are also different systems reported that include organic solvents, e.g., $\mathrm{MeOH}, \mathrm{ACN}$, EtOH, chloroform, acetone, and DMF. Different organic solvents are used in mixtures or in a mixture with aqueous solvents $[4,5]$ and/or other additives like formic acid that enhance the compounds' ionization [4]. Proper optimization of the solvent's composition improves the ionization efficiency and sensitivity of the method [4]. Further improvement of the analyzing capabilities might be observed with some specific modifications of the solvent composition such as in reactive DESI. This technique involves the addition of specific reagents to the solvent, which allows analytes' transformation into forms with enhanced detection abilities. Reactive DESI is a highly selective method devoted to a specific type of compounds $[6,7]$.

\section{Advantages and disadvantages of DESI-MS}

The greatest advantage of DESI-MS technique is time efficiency gained by having no need of complex sample preparation or separation techniques such as extraction and chromatography. The sample is analyzed in shorter time when compared to common analytical techniques and in its native state, straightaway from the surface [2]. However, it must be emphasized that the initial optimization of the analysis' parameters is not always straightforward and might be a long-lasting process due to many variables affecting the signal such as source geometry, source construction, interrogation surface material, instrumental settings, etc. which, moreover, could be interdependent [3].

Furthermore, this technique presents high throughput, sensitivity, specificity, discrimination power and the ability to analyze specimens in wide mass range from simple amino acids through drug molecules, alkaloids, terpenoids, and steroids, to peptides and proteins $[2,8]$ and in different forms, e.g., tablets, gels, liquids, powders or plant material $[2,9]$. The instrumentation is very simple [1] and presents imaging capabilities [10] and potential in field-portable miniaturization [11].

Non-destructive nature is the another advantage of DESIMS. It includes only the destruction of a minute sample's fraction that suffers ionization. An example of typical appearance of a dried blood spot card after DESI analysis is presented in a simplified form at Fig. 1 [12]. However, it must be emphasized that the non-destructiveness strongly depends on the type of a sample. For instance, in terms of tissue analysis commonly used solvents systems, such as methanol/water, completely destroy sample's native morphology. Thus, in medical applications histologically compatible methodologies such as 'morphologically friendly' solvent systems are required to be introduced. Combinations of DMF with other solvents, e.g., ACN, MeOH, ethanol, tetrahydrofuran reported by Eberlin et al. [5] can be referred 
as an example. It has been also reported that DESI-MS enables analytes' pre-concentration through their transformation from large sample surface into much smaller drop surface and, hence, improves measurement sensitivity.

These advantages make DESI-MS a perfect technique for surface analysis, mapping and especially, due to its minimal destructiveness and possible in-situ measurements, for forensic applications [1,2].

The greatest disadvantages of DESI-MS are: possible matrix affection to the efficiency of ionization and droplet formation, measurements automation and reproducibility problems, and still quantification and complex data processing difficulties $[1,2]$. To overcome the drawbacks, some DESI-MS process modifications have been investigated. These include sprayer modification approaches [5] such as reactive DESI $[6,7]$, but also geometry-independent DESI $[13,14]$ and nano-DESI $[15,16]$.

Reactive DESI is a powerful tool while working with samples that are difficult to ionize. The technique is based on enriching the spray solvent with a reactant that interacts with the analyte and thereby allows its ionization and increases both the signal intensity and the ability to detect the compound [7]. As an example, this may serve: the complexation of RDX with the anion $\mathrm{CF}_{3} \mathrm{COO}^{-}[6]$ or the reaction between dicationic compounds and lipids in biological samples [7]. Reactive DESI is a highly selective method that allows targeting molecules of interest. However, this property also reduces its universality [6].

Geometry-independent DESI has been introduced to reduce the influence of experimental parameters and the environment on the analysis. In this technique, all parts of the DESI instrumentation are fixed. Beyond that the solvent delivery line is located oppositely to the ion entrance to the MS inlet. An angle of zero degrees is formed between the lines. Thus, the improvement of the system stability and repeatability of measurements can be obtained which is important in terms of quantitative analysis [13]. Furthermore, geometry-independent DESI simplifies the sample introduction process and enables direct analysis of samples such as fingerprints [14]. The method sensitivity can be further improved by increasing the efficiency of analyte ion collection [13].

In the nano-DESI technique, an analyte is desorbed into a solvent bridge that is formed between two capillaries: primary and nanospray capillary, and the analysis surface. Primary capillary delivers the solvent to create and maintain the bridge, while the nanospray capillary is responsible for the transport of the analyte from the bridge to the mass spectrometer. By applying high voltage, the analyte-containing solvent is removed from the surface to MS and the creation of a self-aspirating nanospray occurs [15]. This technique enables the separation of desorption and ionization events, thus providing their independent control. It also eliminates splashing, allows direct specification of the examined area, and improves the spatial resolution [15, 16]. Nano-DESI has been applied in the direct analysis of complex mixtures of soluble organic and biological molecules such as tissues on different surfaces [16].

\section{Application}

In terms of individualization, suspect's identification and toxicological purposes, the DESI-MS analysis of biological fluids and tissues is of great importance to forensic chemistry. DESI-MS applications in the analysis of three types of biological matrices: fingerprints, skin and biological fluids for detection purposes of drugs, explosives and other chemicals have been reviewed. The study focuses on the latest advances in the use of this technique for forensic purposes published after the Morelato et al.'s review in 2013 [9].

Forensic chemistry deals with the analysis of trace evidence found at the crime scene and/or relevant to the event. DESI-MS technique has presented the ability to detect and identify a broad range of compounds relevant to forensic analysis such as explosives, chemical warfare agents (extremely toxic chemical compounds), GSR, medicines, and drugs of abuse [9]. In forensic practice, these types of evidence can be encountered in different forms such as drugs seized samples [17], tablets [18] and biological matrices [19].

Most studies about DESI-MS applications for drugs analysis focus on pharmaceutical and OCT drugs such as aspirin, caffeine, paracetamol, ibuprofen and sildenafil $\left(\right.$ Viagra $\left.^{\circledR}\right)$ in the form of tablets, creams, gels, plant materials, solutions deposited on different surfaces, e.g., glass slides, filter papers, TLC plates, polymers [9, 18]. Powerful drugs detection (properly the detection of active pharmaceutical ingredients and excipients) has been reported after nano-DESI MS modification that ensures extremely localized desorption [18]. Anticancer drugs with potential genotoxic effects were also analyzed to asses exposure in the hospital workplace. It was proved that the method provides reliable qualitative information with comparable detection limits [20]. Regarding the application for illicit drugs, DESIMS analysis of mephedrone, other synthetic cathinones, and cocaine in authentic drugs' evidence seized samples was successfully reported on different solid surfaces [17, 21-23]. Analyzed surfaces were chosen after optimization so that it would generate the least variable signal. It is worth noting that direct analysis was accomplished from both relatively flat (glass, Teflon ${ }^{\circledR}$ ) and also more complex (acrylic plastic, polyethylene baggies) surfaces with detection limits from low- to sub-ng [22]. Although DESI-MS quantitative analysis resulted in high imprecision and LOD larger than this obtained with GC-MS (for mephedrone $8-2 \mu \mathrm{g} / \mathrm{mL}$ ) [23], 
the technique proved its great potential in the preliminary identification of drugs. Similarly, satisfactory results were obtained for the DESI-MS detection of broad range of explosives such as RDX and TNT on many surfaces, e.g., paper, plastic and metal [24].

The fingerprint evidence is crucial for forensic identification of criminals [25]. However, they may contain more useful forensic information when based on their chemical composition. Fingerprints consist of two types of chemicals: endogenous that are the natural secretions of glands in the skin, and exogenous that might carry a lot of information about the contact with chemicals such as explosives and drugs of abuse [14]. Endogenous components were successfully imaged with the application of DESI-MS and numbers of compounds belonging to various classes of lipids were recorded such as cis-hexadec-6-enoic, acid, stearic acid, cis-octadec-8-enoic acid, palmitic acid, pentadecylic acid, myristic acid, and triacylglycerols [14]. A significant advance in forensic science might be offered by the personal information about gender, ethnicity, and age that was reported to be carried by fingerprints' endogenous lipidomic profiles [26].

DESI-MS detection of exogenous chemicals from fingerprints, which might be relevant to a crime, is of a great importance to forensic chemistry. It might enable the identification of the correlation between the suspect and the materials that he stayed in touch with. The ability to answer this question might be crucial for proper reconstruction of a crime and determination of the person responsible. DESI-MS was successfully applied in imaging of small amounts $(5 \mu \mathrm{g})$ of drugs of abuse such as cocaine and $\Delta 9$-tetrahydrocannabinol and explosives such as RDX from latent fingerprints providing spatial resolution around $150 \mu \mathrm{m}$ [14]. The fingerprints, after exposition of participant's fingers to the compounds' solutions, were deposited and imaged on ordinary surfaces such as glass, paper, and plastic. The DESI-MS imaging was reported to be successful even on tape-lifted fingerprints [14]. Furthermore, the concentration map of cocaine from the fingerprint on paper has been constructed with a limit of detection of above $1 \mathrm{ng}$ of cocaine. It should be also noted that the signals for methamphetamine and heroin from the fingerprint on paper were completely suppressed and it was impossible to obtain any DESI-MS image on silicon surface due to the high velocity spray displacing the printed spots [27]. Moreover, the DESIMS technique was successfully applied for the detection of excreted cocaine and its metabolites-benzoylecgonine and methylecgonine, from fingerprints with limits of detection of $5 \mathrm{ng} / \mathrm{ml}$ and $50 \mathrm{ng} / \mathrm{ml}$, respectively, and had good correlation with oral fluid GC-MS testing [28]. The possibility of imaging metabolites can potentially allow differentiation between drug consumption and other type of contact with a sample such as touch [28]. It should be mentioned also that the determination of fingerprints' distinctive exposure history to chemicals carries a great promise for distinguishing between overlapping fingerprints that is a great limitation in forensic practice [14].

Another interesting DESI-MS application reported for imaging of exogenous chemicals from fingerprints is the detection of chemical components present in condoms as circumstantial evidence of sexual assault [29]. The compounds commonly used in lubricated condoms formulations such as polymers (nonoxynol-9, polyethylene glycol, polydimethylsiloxane) and small molecules additives ( $N$-methylmorpholine, $\mathrm{N}$-octylamine, $\mathrm{N}, \mathrm{N}$-dibutyl formamide, isonox 132 ) were successfully determined by DESI-MS [27]. Moreover, a successful statistical classification of ten types of condoms by DESI-MS with 94\% prediction ability was presented [30]. When handling, chemical components of condoms might be transferred and deposited with the fingerprint. This type of evidence is of a great importance to sexual assaults crimes providing information about both suspect's identity and condom traces [29], especially nowadays when rapists are tending to be increasingly aware of forensic techniques and more alert in leaving biological traces on victims or at the crime scenes [31]. Latent fingerprints containing condom-derived traces were successfully mapped on glass, paper, and metal surfaces after $1 \mathrm{~h}$ from the deposition, with the best quality of results obtained on the former surface. The analysis was still successful after 1 month of aging under ambient conditions with only diminished overall quality of the image but still informative in terms of details [29].

In relation to fingerprints analysis, the DESI-MS application for the detection of exogenous compounds on human skin was successfully reported [32]. It must be noted that in in vivo intact skin DESI-MS analysis particular attention must be drawn to the non-invasiveness of the method. Therefore, the direct contact between the skin and the electrospray tip and the atmospheric inlet of mass spectrometer must be avoided [32]. DESI-MS skin analysis was reported to provide both information about biological metabolism of the subject and exogenous objects such as cosmetics, cleansing agents, food items, or plastics. Thus, the method can be successfully applied in forensic chemistry for the identification of compounds that the suspect has stayed in touch with but also for the excreted ones such as drugs of abuse [32]. Explosives were detected directly on human skin with the use of DESI-MS with detection limits less than 2 ng [33]. Illicit drugs such as cocaine, methamphetamine, and diacetylmorphine in small amounts of $1 \mathrm{ng}$ were successfully analyzed directly from skin (index finger) with high selectivity and sensitivity and with no sample preparation [34]. Moreover, the DESI-MS ability to distinguish between molecules of external and internal origin was proven by the detection of nicotine and its metabolite cotinine from fingertips of a smoker 
and non-smoker who was rubbing a single tobacco leaf strip. The results showed that the nicotine signal from the smoker presented persistent slow decay, however, in terms of non-smoker the nicotine was removed after $10 \mathrm{~min}$. As expected, the metabolite was only detected in the case of smoker's analysis. Furthermore, the study regarding DESI-MS detection of ketamine form the left hind sole of male Wistar rats, after the use of sodiated creatinine as an internal standard, has presented acceptable similarity to the results of rats' DBS samples LC-MS analysis of ketamine [32].

Finally, DESI-MS analysis of complex biological matrices, which are of great importance to forensic chemistry in terms of toxicological analysis of drugs, has been reported. Illicit drugs, opiates, and benzodiazepines in urine spotted on different surfaces have been analyzed after solvent extraction [9]. The analysis of steroid esters in hair specimens, after rapid ultrasonic extraction, has been also investigated [35]. Another extraction based example is fast and sensitive profiling of drug-esomeprazole and its metabolites in rat plasma [36] and liquid extraction surface analysis of drugs in rat liver tissue [37] which presented comparable quantitative results to these obtained with LC-MS/MS method. Drugs were successfully analyzed at the therapeutic concentration levels with a small volume of extract; for esomeprazole excellent linearity $\left(r^{2}=0.987\right)$ was obtained in the $0.2-20 \mu \mathrm{g} / \mathrm{mL}$ concentration range. It was also proved that extraction procedure was necessary for the effective determination because results obtained for direct plasma samples spiked with esomeprazole were not suitable for pharmacokinetic studies [36].

The need for an extraction procedure of drugs from biological matrices extends the sample preparation stage and so the whole DESI-MS analysis process that is unfavorable from the forensic chemistry point of view where rapid traces' analysis is necessary. To overcome this issue, the combination of DESI-MS with Thin Liquid Membrane Extraction was reported [19]. The average total analysis time was shortened to less than 1 min per sample. The TLMEDESI technique was successfully used for the analysis of drugs such as methadone, amitriptyline, nortriptyline, and diphenhydramine in different biological matrices: urine, saliva and whole-blood at clinically relevant concentrations. Drugs were studied in the concentration range of $100-1000 \mathrm{ng} / \mathrm{mL}$ capturing their therapeutic ranges such as for methadone- $100-500 \mathrm{ng} / \mathrm{mL}$. Although LODs reported were somewhat higher than those obtained with common chromatographic methods, they could be fully accepted for work with real samples [19]. Another interesting DESI-MS application with great potential to forensic toxicology is successful localization and quantification of drugs in rat brain tissue with no need of extraction. The quantification results obtained were in excellent agreement with LC-MS/MS [38].
Further advance in forensic science can be offered by DESI-MS in terms of direct in-source analysis of biological fluids spotted on paper or other appropriate surfaces (e.g. Guthrie's card)—dried blood spots [12]. As in the DBS most common applications, metabolic disorders diagnosis, especially in neonatal screening, therapeutic drugs monitoring, and toxicological analysis can be performed by recording DESI-MS spectra [10]. For the first time, DESI-MS analysis of DBS for drugs of abuse was done in 2006 when it was applied for cocaine and amphetamine-like screening. Although the sensitivity was really poor due to severe matrix effects (LOD 100 times higher than toxicologically relevant levels), the results should be treated as a snapshot of the DESI-MS potential at a certain time with a certain instrumentation. Further studies have improved the DESIMS sensitivity through some process modification [12]. The use of novel three-layer setup for quantitative therapeutic monitoring of salicylic acid on dried blood spot has proved to present good agreement with LC-MS/MS results. Moreover, in this study the dynamic ranges reported for three different matrices: whole blood, human plasma and saline covered the drug full therapeutic range-from 30 to $300 \mathrm{mg} / \mathrm{L}(8-4000 \mathrm{mg} / \mathrm{L}, 4-4000 \mathrm{mg} / \mathrm{L}, 2-2000 \mathrm{mg} / \mathrm{L}$, respectively, higher ranges for less complicated matrices). The curves obtained for all three matrices were linear with coefficients of determination greater than 0.997 [39]. These results carry a great promise for the application of DESIMS in personalized health care and also minimally invasive forensic toxicology.

Summary of the DESI-MS forensic applications is compiled in Table 1. In order not to duplicate the data, Table 1 does not contain results included in a review a few years earlier published by Morelato et al. [9].

DESI-MS method has also proved its potential in many other non-forensic applications such as food control analysis of multiple pesticides on different food surfaces [40], analysis of drugs in wastewater [41], veterinary drugs in feedstuffs [42], lubricant oil additives [43] and clinical diagnostics [21, 46]. Research shows great DESI-MS potential in the analysis of lipids, proteins, protein complexes, carbohydrates, and oligonucleotides, specimens from industrial polymers to small organic molecules [44]. Furthermore, the ability to perform spatial in situ imaging of biological samples seems to be particularly useful, especially in case of medical cancer diagnosis [46]. In vivo alkaloids distribution mapping in plant tissue such as Atropa belladonna was the earliest demonstration of DESI-MS imaging capability [10]. Then, imaging of biological tissues' fatty acids and lipids in rat brain and whole body zebra fish tissues, after specific process modification, has been reported [44, 45]. Very important nowadays, application in cancer diagnostics has also been studied, such as prostate cancer diagnosis based on identifying differences in the distribution of various metabolites and 


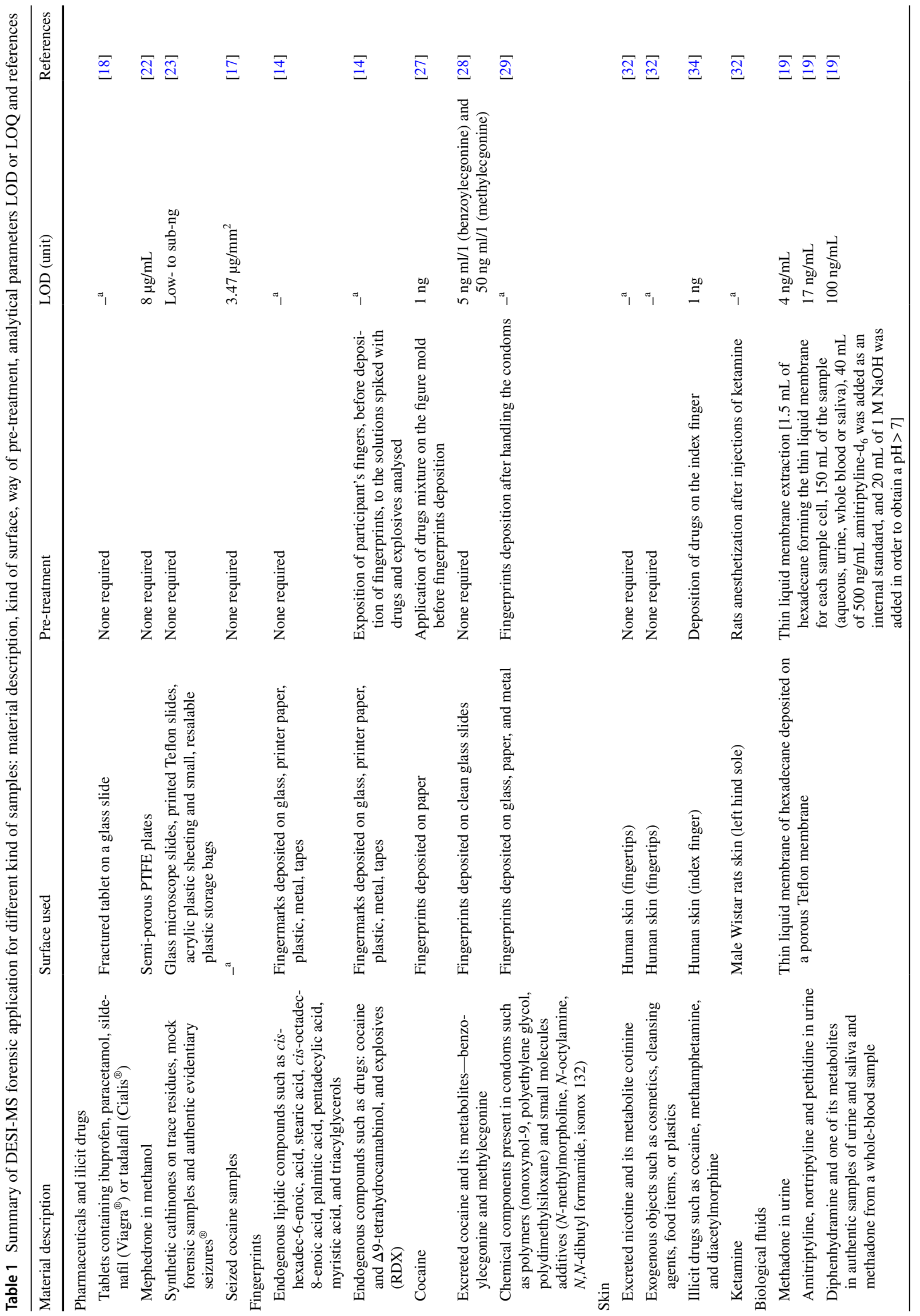


lipids between cancerous and normal prostate tissues [46]. Furthermore, DESI-MS imaging has been applied during surgeries as a tool assisting with pathological information based mainly on lipid profiles [8]. These examples present a great promise also for forensic screening of drugs in complex biological matrices.

\section{Conclusion}

The latest DESI-MS applications in the forensic analysis of biological fluids and tissues have been reviewed. Advances in the technique's use for forensic purposes applied after the last review by Morelato et al. [9] have been studied and summarized.

DESI-MS is a promising analytical technique that enables ambient ionization and surface in-situ analysis. It is fast, does not require complicated instrumentation and sample preparation, and presents big discrimination power. Many DESI-MS applications in forensics, medical diagnostics and food control have been reported in the literature. Above all, rapid, direct, in-source forensic monitoring of compounds in complex biological matrices seems to be very important. Illicit drugs and other type of chemicals of external and internal origin have been successfully detected and imaged from fingerprints, on skin and in biological fluids with the use of DESI-MS. The DESI-MS was applied also for the analysis of drugs on dried blood spots, biological fluids spotted and dried on appropriate surfaces. Despite the fact that DESI-MS due to its low repeatability, reproducibility, and still troublesome quantification cannot currently replace common techniques such as GC-MS and LC-MS, it carries a great promise for screening and preliminary identification of drugs and other chemicals in biological matrices. DESI-MS analysis and imaging show a great potential that still needs to be studied and developed in future research.

Acknowledgements The author gratefully acknowledge the Ministry of Science and Higher Education, National Science Centre, Poland for financial support (R. Wietecha-Posłuszny, Sonata Bis 6, no. 2016/22/E/ ST4/00054).

Open Access This article is distributed under the terms of the Creative Commons Attribution 4.0 International License (http://creativeco mmons.org/licenses/by/4.0/), which permits unrestricted use, distribution, and reproduction in any medium, provided you give appropriate credit to the original author(s) and the source, provide a link to the Creative Commons license, and indicate if changes were made.

\section{References}

1. Z. Takats, J.M. Wiseman, B. Gologan, R.G. Cooks, Mass spectrometry sampling under ambient conditions with desorption 
electrospray ionization. Science 306, 471-473 (2004). https:// doi.org/10.1126/science.1104404

2. R.G. Cooks, Z. Ouyang, Z. Takats, J.M. Wiseman, Ambient mass spectrometry. Science 311(5767), 1566-1570 (2006). https://doi. org/10.1126/science.1119426

3. K.A. Douglass, S. Jain, W.R. Brandt, A.R. Venter, Deconstructing desorption electrospray ionization: independent optimization of desorption and ionization by spray desorption collection. J. Am. Soc. Mass Spectrom. 23, 1896-1902 (2012). https://doi. org/10.1007/s13361-012-0468-x

4. F.M. Green, T.L. Salter, I.S. Gilmore, P. Stokes, G. O'Connor, The effect of electrospray solvent composition on desorption electrospray ionisation (DESI) efficiency and spatial resolution. Analyst 135, 731-737 (2010). https://doi.org/10.1039/B924208B

5. L.S. Eberlin, C.R. Ferreira, A.L. Dill, D.R. Ifa, L. Cheng, R. Graham Cooks, Nondestructive, histologically compatible tissue imaging by desorption electrospray ionization mass spectrometry. ChemBioChem 12, 2129-2132 (2011). https://doi.org/10.1002/ cbic. 201100411

6. I. Cotte-Rodríguez, Z. Takáts, N. Talaty, H. Chen, R.G. Cooks, Desorption electrospray ionization of explosives on surfaces: sensitivity and selectivity enhancement by reactive desorption electrospray ionization. Anal. Chem. 77, 6755-6764 (2005). https:// doi.org/10.1021/ac050995

7. D. Lostun, C.J. Perez, P. Licence, D.A. Barrett, D.R. Ifa, Reactive DESI-MS imaging of biological tissues with dicationic ionpairing compounds, Anal. Chem. 87, 3286-3293 (2015). https:// doi.org/10.1021/ac5042445

8. C.S. Clendinen, M.E. Monge, F.M. Fernández, Ambient mass spectrometry in metabolomics. Analyst 142, 3101 (2017). https ://doi.org/10.1039/c7an00700k

9. M. Morelato, A. Beavis, P. Kirkbride, C. Roux, Forensic applications of desorption electrospray ionisation mass spectrometry (DESI-MS). Forensic Sci. Int. 226, 10-21 (2013). https://doi. org/10.1016/j.forsciint.2013.01.011

10. Z. Takats, J.M. Wiseman, R.G. Cooks, Ambient mass spectrometry using desorption electrospray ionization (DESI): instrumentation, mechanisms and applications in forensics, chemistry, and biology. J. Mass Spectrom. 40, 1261-1275 (2005). https://doi. org/10.1002/jms. 922

11. C.C. Mulligan, N. Talaty, R.G. Cooks, Desorption electrospray ionization with a portable mass spectrometer: in situ analysis of ambient surfaces. Chem. Commun. 16, 1709-1711 (2006). https ://doi.org/10.1039/B517357D

12. M. Wagner, D. Tonoli, E. Varesio, G. Hopfgartner, The use of mass spectrometry to analyze dried blood spots. Mass Spectrom. Rev. 35, 361-438 (2016). https://doi.org/10.1002/mas.21441

13. A. Venter, R.G. Cooks, Desorption electrospray ionization in a small pressure-tight enclosure. Anal. Chem. 79, 6398-6403 (2007). https://doi.org/10.1021/ac0708846

14. D.R. Ifa, N.E. Manicke, A.L. Dill, R.G. Cooks, Latent fingerprint chemical imaging by mass spectrometry. Science 321, 805 (2008). https://doi.org/10.1126/science.1157199

15. P.J. Roach, J. Laskin, A. Laskin, Nanospray desorption electrospray ionization: an ambient method for liquid-extraction surface sampling in mass spectrometry. Analyst 135, 2233-2236 (2010). https://doi.org/10.1039/c0an00312c

16. J. Laskin, B.S. Heath, P.J. Roach, L. Cazares, O.J. Semmes, Tissue imaging using nanospray desorption electrospray ionization mass spectrometry. Anal. Chem. 84, 141-148 (2012). https://doi. org/10.1021/ac2021322

17. N. Stojanovska, M. Tahtouh, T. Kelly, A. Beavis, S. Fu, Qualitative analysis of seized cocaine samples using desorption electrospray ionization-mass spectrometry (DESI-MS). Drug Test. Anal. 7, 393-400 (2015). https://doi.org/10.1002/dta.1684
18. C. Cardoso-Palacios, I. Lanekoff, Direct analysis of pharmaceutical drugs using nano-DESI MS. J. Anal. Methods Chem. (2016). https://doi.org/10.1155/2016/3591908. (Article ID 3591908, 6 pages).

19. C. Rosting, S. Pedersen-Bjergaard, S. Honor'e Hansen, C. Janfelt, High-throughput analysis of drugs in biological fluids by desorption electrospray ionization mass spectrometry coupled with thin liquid membrane extraction. Analyst 138, 5965-5972 (2013). https://doi.org/10.1039/c3an00544e

20. G. Fabrizi, M. Fioretti, L. Mainero Rocca, R. Curini, DESI-MS2: a rapid and innovative method for trace analysis of six cytostatic drugs in health care setting. Anal. Bioanal. Chem. 403, 973-983 (2012). https://doi.org/10.1007/s00216-011-5626-7.

21. A.E. O'Leary, H. Oberacher, S.E. Hall, C.C. Mulligan, Combining a portable, tandem mass spectrometer with automated library searching - an important step towards streamlined, on-site identification of forensic evidence. Anal. Methods 7, 3331-3339 (2015). https://doi.org/10.1039/C4AY02778G

22. N. Stojanovska, M. Tahtouh, T. Kelly, A. Beavis, S. Fu, Presumptive analysis of 4-methylmethcathinone (mephedrone) using desorption electrospray ionisation-mass spectrometry (DESIMS). Aust. J. Forensic Sci. 46, 411-423 (2014). https://doi. org/10.1080/00450618.2013.879206

23. K.E. Vircks, C.C. Mulligan, Rapid screening of synthetic cathinones as trace residues and in authentic seizures using a portable mass spectrometer equipped with desorption electrospray ionization. Rapid Commun. Mass Spectrom. 26, 2665-2672 (2012). https://doi.org/10.1002/rcm.6390

24. Z. Takats, I. Cotte-Rodriguez, N. Talaty, H. Chen, R.G. Cooks, Direct, trace level detection of explosives on ambient surfaces by desorption electrospray ionization mass spectrometry. Chem. Commun. 15, 1950-1952 (2005). https://doi.org/10.1039/B4186 97D

25. G. Payne, B. Reedy, C. Lennard, B. Comber, D. Exline, C. Roux, A further study to investigate the detection and enhancement of latent fingerprints using visible absorption and luminescence chemical imaging. Forensic. Sci. Int. 150(1), 33-51 (2005). https ://doi.org/10.1016/j.forsciint.2004.06.036

26. Z. Zhou, R.N. Zare, Personal information from latent fingerprints using desorption electrospray ionization mass spectrometry and machine learning. Anal. Chem. 89(2), 1369-1372 (2017). https ://doi.org/10.1021/acs.analchem.6b04498

27. S. Muramoto, T.P. Forbes, A.C. van Asten, G. Gillen, A novel test sample for the spatially resolved quantification of illicit drugs on fingerprints using imaging mass spectrometry. Anal. Chem. 87, 5444-5450 (2015). https://doi.org/10.1021/acs.analchem.5b010 60

28. M.J. Bailey, R. Bradshaw, S. Francese, T.L. Salter, C. Costa, M. Ismail, R.P. Webb, I. Bosman, K. Wolff, M. de Puit, Rapid detection of cocaine, benzoylecgonine and methylecgonine in fingerprints using surface mass spectrometry. Analyst 140, 6254-6259 (2015). https://doi.org/10.1039/C5AN00112A

29. M.F. Mirabelli, A. Chramow, E.C. Cabral, D.R. Ifa, Analysis of sexual assault evidence by desorption electrospray ionization mass spectrometry. J. Mass Spectrom. 48, 774-778 (2013). https://doi. org/10.1002/jms.3205

30. M.F. Mirabelli, D.R. Ifa, G. Sindona, A. Tagarelli, Analysis of sexual assault evidence: statistical classification of condoms by ambient mass spectrometry. J. Mass Spectrom. 50, 749-755 (2015). https://doi.org/10.1002/jms.3584

31. R.D. Blackledge. Forensic Analysis on the Cutting Edge: New Methods for Trace Evidence Analysis (Wiley, Hoboken, 2007)

32. M. Katona, J. Denes, R. Skoumal, M. Toth, Z. Takats, Intact skin analysis by desorption electrospray ionization mass spectrometry. Analyst 136, 835-840 (2011). https://doi.org/10.1039/c0an00688b 
33. D.R. Justes, N. Talaty, I. Cotte-Rodriguez, R.G. Cooks, Detection of explosives on skin using ambient ionization mass spectrometry. Chem. Commun. 21, 2142-2144 (2007). https://doi.org/10.1039/ b703655h

34. I. Cotte-Rodriguez, C.C. Mulligan, R.G. Cooks, Non-proximate detection of small and large molecules by desorption electrospray ionization and desorption atmospheric pressure chemical ionization mass spectrometry: instrumentation and applications in forensics, chemistry, and biology. Anal. Chem. 79, 7069-7077 (2007). https://doi.org/10.1021/ac0707939

35. M.W. Nielen, A.W. Nijrolder, H. Hooijerink, A.A. Stolker, Feasibility of desorption electrospray ionization mass spectrometry for rapid screening of anabolic steroid esters in hair. Anal. Chim. Acta 700(1-2), 63-69 (2011). https://doi.org/10.1016/j. aca.2010.08.009

36. A. Rossi, L. Castrati, P. Colombo, L. Flammini, E. Barocelli, R. Bettini, L. Elviri, Development and validation of a DESI-HRMS/ MS method for the fast profiling of esomeprazole and its metabolites in rat plasma: a pharmacokinetic study. Drug Test. Anal. 8, 208-213 (2016). https://doi.org/10.1002/dta.1805

37. J.G. Swales, N. Strittmatter, J.W. Tucker, M.R. Clench, P.J.H. Webborn. R.J.A. Goodwin, Spatial quantitation of drugs in tissues using liquid extraction surface analysis mass spectrometry imaging. Sci. Rep. 6, 37648 (2016). https://doi.org/10.1038/srep3 7648

38. R. Vismeh, D.J. Waldon, Y. Teffera, Z. Zhao, Localization and quantification of drugs in animal tissues tby use of desorption electrospray ionization mass spectrometry imaging, Anal. Chem. 84, 5439-5445 (2012). https://doi.org/10.1021/ac3011654

39. M. Siebenhaar, K. Küllmer, N. Miguel de Barros Fernandes, V. Hüllen, C. Hopf, Personalized monitoring of therapeutic salicylic acid in dried blood spots using a three-layer setup and desorption electrospray ionization mass spectrometry. Anal. Bioanal. Chem. 407, 7229-7238 (2015). https://doi.org/10.1007/s0021 6-015-8887-8

40. S. Gerbig, G. Stern, H.E. Brunn, R. Düring, B. Spengler, S. Schulz, Method development towards qualitative and semi-quantitative analysis of multiple pesticides from food surfaces and extracts by desorption electrospray ionization mass spectrometry as a preselective tool for food control. Anal. Bioanal. Chem. 409, 2107-2117 (2017). https://doi.org/10.1007/ s00216-016-0157-x

41. N. Strittmatter, R.A. During, Z. Takats, Analysis of wastewater samples by direct combination of thin-film microextraction and desorption electrospray ionization mass spectrometry. Analyst 137, 4037-4044 (2012). https://doi.org/10.1039/c2an35411j

42. R. Seró, O. Núñez, J. Bosch, J.M. Grases, P. Rodríguez, E. Moyano, M.T. Galceran, Desorption electrospray ionization-high resolution mass spectrometry for the screening of veterinary drugs in cross-contaminated feedstuffs. Anal. Bioanal. Chem. 407, 7369-7378 (2015). https://doi.org/10.1007/s00216-015-8899-4

43. C.Da Costa, J.C. Reynolds, S. Whitmarsh, T. Lynch, C.S. Creaser, The quantitative surface analysis of an antioxidant additive in a lubricant oil matrix by desorption electrospray ionization mass spectrometry. Rapid Commun. Mass Spectrom. 27, 2420-2424 (2013). https://doi.org/10.1002/rcm.6690

44. T.S. Hamid, D. Lostun, E.C. Cabral, R. Garrett, D.K. Bohme, D.R. Ifa, Comparisons of ambient spray ionization imaging methods. Int. J. Mass Spectrom. 377, 736-743 (2015). https:// doi.org/10.1016/j.ijms.2014.07.035

45. J. Tillner, V. Wu, E.A. Jones, S.D. Pringle, T. Karancsi, A. Dannhorn, K. Veselkov, J.S. McKenzie, Z. Takats, Faster, more reproducible DESI-MS for biological tissue imaging. J. Am. Soc. Mass Spectrom. 28, 2090-2098 (2017). https://doi.org/10.1007/s1336 $1-017-1714-z$

46. S. Banerjee, R.N. Zare, R.J. Tibshirani, C.A. Kunder, R. Nolley, R. Fan, J.D. Brooks, G.A. Sonn, Diagnosis of prostate cancer by desorption electrospray ionization mass spectrometric imaging of small metabolites and lipids. PNAS 114, 3334-3339 (2017). https ://doi.org/10.1073/pnas.1700677114

Publisher's Note Springer Nature remains neutral with regard to jurisdictional claims in published maps and institutional affiliations. 